\title{
Salt sensitivity and circadian rhythm of blood pressure: the keys to connect CKD with cardiovasucular events
}

\author{
Genjiro Kimura, Yasuaki Dohi and Michio Fukuda
}

In healthy subjects, blood pressure (BP) drops by 10-20\% during the night. Conversely, in patients with the salt-sensitive type of hypertension or chronic kidney disease, nighttime BP does not fall, resulting in an atypical pattern of circadian BP rhythm that does not dip. This pattern is referred to as the 'non-dipper' pattern. Loss of renal functional reserve, due to either reduced ultrafiltration capacity or enhanced tubular sodium reabsorption, induces the salt-sensitive type of hypertension. When salt intake is excessive in patients with salt-sensitive hypertension, the defect in sodium excretory capability becomes evident, resulting in elevated BP during the night. This nocturnal hypertension compensates for diminished natriuresis during the daytime and enhances pressure natriuresis during the night. Nocturnal hypertension and the non-dipper pattern of circadian BP rhythm cause cardiovascular events. When excess salt intake is loaded in patients who are in a salt-sensitive state, glomerular capillary pressure is also elevated, resulting in glomerular sclerosis and eventual renal failure. In this way, salt sensitivity and excess salt intake contribute to both cardiovascular and renal damage at the same time. We propose that salt sensitivity of BP and excess salt intake have important roles in the genesis of the cardiorenal connection. Salt sensitivity and circadian rhythm of BP are the keys to understanding the connections between cardiovascular and renal complications. Hypertension Research (2010) 33, 515-520; doi:10.1038/hr.2010.47; published online 9 April 2010

Keywords: circadian rhythm; kidney; natriuresis; non-dipper; salt

\section{INTRODUCTION}

High blood pressure (BP) is one of the strongest risk factors for cardiovascular disease. ${ }^{1}$ Kidneys are considered the essential organ to control BP, and it seems impossible to cause hypertension without a disturbance in renal function. ${ }^{2-9}$ Therefore, we may conclude that most cardiovascular diseases originate from renal dysfunction. Microalbuminuria involves the excretion of a small quantity of albumin into the urine. The condition has attracted attention as a predictor of future nephropathy in diabetes mellitus and is now widely accepted as a risk predictor for cardiovascular events in hypertension and among the general population. ${ }^{10-14}$ Albuminuria is considered as a risk predictor rather than a risk factor because the precise mechanisms by which albuminuria causes cardiovascular events remain unknown. Conversely, in patients with renal dysfunction, even mild cases, cardiovascular events occur as frequently as in patients with previous myocardial infarction and diabetes mellitus. ${ }^{15-18}$ These findings lead us to assume that chronic kidney disease (CKD), defined as the presence of proteinuria or renal dysfunction for more than 3 months, ${ }^{19}$ seems to be a strong risk factor or predictor of cardiovascular events.

In this review, we discuss the mechanisms underlying connections between the cardiovascular and renal systems, with regard to the salt sensitivity and circadian rhythm of BP.

\section{SALT SENSITIVITY AND CARDIOVASCULAR EVENTS}

We have shown that salt sensitivity of BP is an independent prognostic factor in essential hypertension. ${ }^{20,21}$ A total of 156 patients with essential hypertension were placed on a high-salt $(12-15 \mathrm{~g} \mathrm{NaCl}$ per day) diet and on a low-salt (1-3g per day) diet for 1 week each in randomized order to determine salt sensitivity. ${ }^{20,22-25}$ Patients were then followed up for $7.3 \pm 4.3$ years until the occurrence of end points such as ischemic heart disease or stroke. Patients whose BP was lowered more than $10 \%$ by salt intake restriction were considered to be salt sensitive $(n=62)$; the other patient population was considered non-salt sensitive $(n=94)$. During the follow-up period, cardiovascular events occurred in 14 cases (including 3 fatal events) in the nonsalt-sensitive group; cardiovascular events occurred in 17 cases (5 fatal) in the salt-sensitive group. There were two cardiovascular morbid events per 100 patient-years in the non-salt-sensitive group and 4.3 in the salt-sensitive group. The cardiovascular morbid eventfree survival curve was significantly worse in the salt-sensitive group. Cox's proportional hazards model identified salt sensitivity as an additional risk independent of BP level, smoking and hypercholesterolemia. These results show that cardiovascular morbidity was higher in the salt-sensitive type of essential hypertension than in the non-saltsensitive type. This finding has been confirmed by Weinberger et al., ${ }^{26}$ 
who showed that even in normotensive subjects salt sensitivity is an independent risk factor for cardiovascular events.

Salt sensitivity is controlled by the kidneys, ${ }^{7,24,27}$ and BP characterized by high salt sensitivity indicates a loss of renal functional reserve. ${ }^{7,28} \mathrm{BP}$ becomes salt sensitive when the ultrafiltration capability of the glomerulus is reduced, as seen in $\mathrm{CKD}$, or when renal tubular reabsorption of sodium is enhanced, as seen in primary aldosteronism, diabetes mellitus and metabolic syndrome. ${ }^{7,29}$ Glomerular filtration rate (GFR) is usually reduced in CKD but enhanced in primary aldosteronism, diabetes mellitus and metabolic syndrome. It should be noted here that salt sensitivity of BP is enhanced even in patients whose GFR is elevated when tubular sodium reabsorption is augmented.

\section{SALT SENSITIVITY AND CIRCADIAN RHYTHM OF BLOOD PRESSURE}

There is a close relationship between salt sensitivity of BP and the nondipper pattern of circadian BP rhythm ${ }^{29-31}$ (Figure 1). In patients with high salt sensitivity, the nocturnal dip in $\mathrm{BP}$ is diminished irrespective of the mechanisms causing salt sensitivity. For example, in both the salt-sensitive type of essential hypertension ${ }^{32,33}$ and primary aldosteronism, ${ }^{34}$ in which reduced ultrafiltration capability and enhanced tubular sodium reabsorption, respectively, cause salt sensitivity, $7,24,27,35,36$ non-dipper patterns of circadian BP rhythm are observed. ${ }^{29,30}$

The circadian rhythm of urinary sodium excretion rate was compared between two groups with different circadian BP rhythms. ${ }^{37}$ In dippers, the night/day ratios of both $\mathrm{BP}$ and sodium excretion were less than 0.9 , even when patients were on a high-salt diet, exhibiting normal circadian rhythms with nocturnal dips. In nondippers, however, these ratios were significantly higher than in dippers. In particular, the night/day ratio of sodium excretion was greater than 1 in non-dippers, indicating that urinary sodium excretion was enhanced during the night. Salt restriction significantly lowered the night/day ratios of both $\mathrm{BP}$ and sodium excretion in non-dippers, whereas these ratios remained unchanged and below 1 in dippers, independent of the amount of salt intake. ${ }^{37}$

There was a strong positive relationship between night/day ratios of BP and sodium excretion observed in patients on a high-salt diet ${ }^{37,38}$ but not in patients on a low-salt diet, ${ }^{37}$ suggesting that sodium excretion was dependent on systemic BP in patients with high-salt intake (especially in non-dippers), but not in patients with low-salt
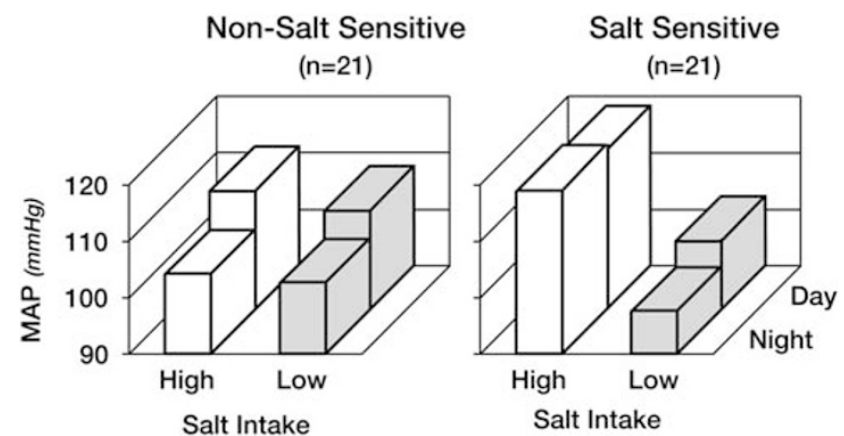

Figure 1 Effects on mean arterial pressure of salt intake restriction and nocturnal drops in non-salt-sensitive (left panel) and salt-sensitive (right panel) types of essential hypertension. Two-way analysis of variance clearly showed that diminished nocturnal BP decline was restored by salt restriction, and the circadian rhythm of $\mathrm{BP}$ was shifted from the non-dipper pattern to the dipper pattern in this type of essential hypertension. MAP, mean arterial pressure. Modified from Uzu et al. ${ }^{33}$ intake. It is clear now that in patients with salt-sensitive BP, the circadian rhythms of both BP and urinary sodium excretion were all disturbed. ${ }^{30,37,38}$ Salt restriction restored these rhythms from nondipper to dipper patterns. ${ }^{30,32-34,37}$

\section{RENAL DYSFUNCTION AND NON-DIPPER CIRCADIAN RHYTHMS}

Because glomerular filtration capability is one of the major factors determining salt sensitivity, $7,24,28,36$ the nocturnal dip in BP may be less pronounced as a function of GFR loss. We recently showed this quantitative relationship in $\mathrm{CKD}^{38,39}$ and healthy donors after nephrectomy, ${ }^{40}$ in both of whom there was an inverse relationship between GFR and the night/day ratio of BP. These findings are compatible with high salt sensitivity of BP in glomerulopathy, even when GFR is maintained at a relatively normal level, ${ }^{41,42}$ ultimately becoming much higher as renal function deteriorates. ${ }^{43,44}$ These findings are also compatible with the proposal that as the number of nephrons is reduced BP becomes more salt sensitive. ${ }^{7,35,45,46}$ Alternatively, the non-dipper pattern of circadian BP rhythm is often considered to be a risk factor for the progression of nephropathy. ${ }^{4-52}$ Because the degree of non-dipping was closely correlated with the degree of renal function loss, as discussed above, ${ }^{38,40}$ however, non-dipping might be consequently correlated with the progression of nephropathy. Our clear results especially obtained after kidney donation $^{40}$ that instead it might be a phenotype of renal functional loss, together with well known facts that in patients with renal dysfunction the nocturnal BP dip is lost and circadian rhythms manifest as those of non-dippers, ${ }^{38,40,47,50,53,54}$ suggest that the circadian rhythm of BP is determined mostly by the kidneys. The importance of kidneys in the genesis of circadian BP rhythm is consistent with reports that the circadian rhythm of BP is normalized from non-dipper to dipper after kidney transplantation, ${ }^{55}$ and also by salt intake restriction and diuretics. ${ }^{33,34,56-58}$

In most non-dippers with essential hypertension, CKD, diabetes mellitus or primary aldosteronism, renal functional reserve is impaired. ${ }^{28-30}$ In rare cases, a non-dipper pattern is caused by something other than kidney function (Table 1), such as sleep apnea syndrome, stroke or working a day-night shift, which disturbs sleeping rhythm. Furthermore, disorders such as pheochromocytoma and Cushing syndrome disturb the secretion rhythms of BP-regulating

Table 1 Theoretical classification of disorders causing non-dipper pattern of circadian blood pressure rhythm

\begin{tabular}{|c|c|c|}
\hline Pathophysiology & Mechanisms & Disorders \\
\hline \multicolumn{2}{|c|}{ Disturbance in sleeping rhythm } & Sleep apnea syndrome \\
\hline & & Stroke \\
\hline & & Day-night shift workers \\
\hline \multirow{2}{*}{\multicolumn{2}{|c|}{ Disturbance in secretion rhythm of vasoactive hormone }} & Pheochromocytoma \\
\hline & & Cushing syndrome \\
\hline \multirow{7}{*}{$\begin{array}{l}\text { Impaired renal capacity } \\
\text { to excrete sodium } \\
\text { (salt-sensitive } \\
\text { hypertension) }\end{array}$} & \multirow{4}{*}{$\begin{array}{l}\text { Reduced ultrafiltration } \\
\text { capability }\end{array}$} & CKD \\
\hline & & Hypertension in black \\
\hline & & Salt-sensitive type of \\
\hline & & essential hypertension \\
\hline & \multirow{3}{*}{$\begin{array}{l}\text { Enhanced tubular } \\
\text { sodium reabsorption }\end{array}$} & Primary aldosteronism \\
\hline & & Diabetes mellitus \\
\hline & & Metabolic syndrome \\
\hline
\end{tabular}

Abbreviation: CKD, chronic kidney disease.

Orthostatic hypotension must be deleted from this list, because BP is totally dependent on the position of the body rather than circadian rhythm of life. Reproduced from Kimura. ${ }^{29}$ 
hormones, including catecholamine and corticosteroid. Many diseases causing orthostatic hypotension must be excluded from the list of non-dippers because BP is completely dependent on the position of the body but not on circadian rhythm of life. ${ }^{29}$

\section{MECHANISMS UNDERLYING THE NON-DIPPER PATTERN OF CIRCADIAN BP RHYTHM}

Our recent studies ${ }^{29}$ suggest that diminished renal sodium excretory capability, recognized in the salt-sensitive type of hypertension and CKD, determines the circadian rhythm of BP. When salt intake is high, the defect in sodium excretory capability becomes evident, resulting in elevated nighttime BP. This non-dipper pattern compensates for diminished natriuresis during the daytime and enhances pressure natriuresis during the night. Conversely, when salt intake is low, the defect remains latent, resulting in lowered BP during the night, that is, the dipper profile. If pressure natriuresis during the night compensates for reduced sodium excretion from the kidneys during the daytime, high BP may continue during the night until enough excess sodium is excreted in the urine. Therefore, as renal function deteriorates, more time may be required to excrete sodium by pressure natriuresis during the night before BP begins to dip. ${ }^{31,59}$ We examined whether the time period, defined as 'dipping time', until nocturnal mean arterial pressure fell below $90 \%$ of the daytime average, became longer as renal function deteriorated. BP profiles during the night were compared among three groups of patients with CKD with different levels of renal function ${ }^{59}$ (Figure 2). In the first tertile with relatively normal GFR, BP dropped below $90 \%$ of daytime averages soon after the patient fell asleep. In the third tertile with advanced renal dysfunction, on the other hand, BP remained elevated above daytime averages throughout the night. BP in the second tertile was intermediate to that observed in the first and third tertiles. The duration until nocturnal BP fell was inversely correlated with GFR and positively correlated with night/day ratios of mean arterial pressure and natriuresis.

These findings show that BP takes longer to drop during the night among patients with renal dysfunction. This is an essential component

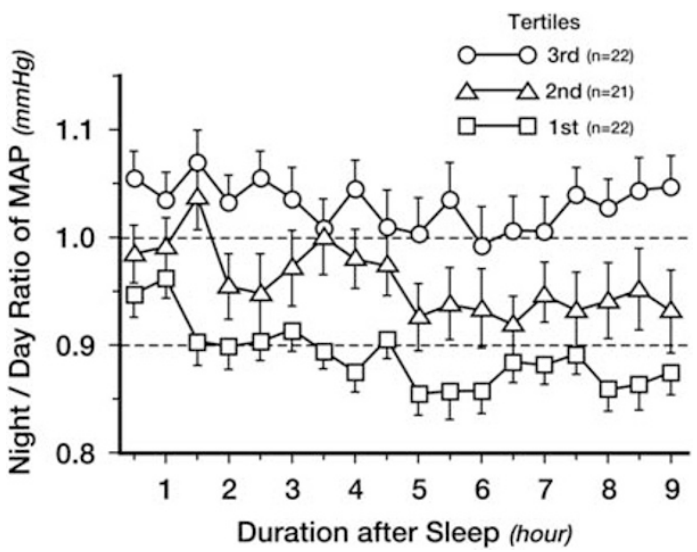

Figure 2 Blood pressure profiles during the night. Ordinate indicates the nocturnal mean arterial pressure (MAP) as the ratio of daytime averages. Subjects were divided into three groups with different levels of renal function based on creatinine clearance $\left(\mathrm{Ccr} \mathrm{ml} \mathrm{min}{ }^{-1}\right)$ : first tertile $(\mathrm{Ccr}, 91-$ 164; $n=22$ ), second tertile ( $\mathrm{Ccr}, 50-90 ; n=21$ ) and third tertile (Ccr, 5-41; $n=22$ ). As renal function deteriorated from the first tertile to the third tertile, nighttime blood pressure exceeded daytime averages and rarely fell below $90 \%$ of the daytime averages during sleep. Error bars indicate the upper and/or lower half of standard error. Modified from Fukuda et al. ${ }^{59}$ of the non-dipper pattern of the circadian BP rhythm. Dipping time may represent a novel index with which to quantify the circadian BP rhythm.

\section{SALT SENSITIVITY AND STROKE}

In addition to the non-dipper pattern, the salt sensitivity of BP is closely linked to glomerular capillary hypertension ${ }^{28,46,60}$ and insulin resistance. ${ }^{61-66}$ The non-dipper pattern, ${ }^{67-73}$ microalbuminuria ${ }^{74,75}$ (a marker for glomerular capillary hypertension), ${ }^{76,77}$ insulin resistance and metabolic syndrome $\mathrm{e}^{78-81}$ are all known to be strong risk factors for cardiovascular events. Therefore, in the salt-sensitive state, several risk factors are clustered together, leading to future cardiovascular events and renal failure. ${ }^{20,21,26,82-86}$

In our follow-up study ${ }^{20}$ of essential hypertensive patients with known salt sensitivity, 31 cardiovascular events were documented during the follow-up period. Of these, 21 were stroke. ${ }^{20}$ Conversely, it has been reported that hypertensive subjects with high plasma renin activity, especially white men, are more likely to have subsequent myocardial infarction. ${ }^{87,88}$ Because, in general, high plasma renin is associated with low salt sensitivity (non-salt sensitivity) and low renin is associated with high salt sensitivity, the reports cited above seem to contradict our hypothesis. However, the authors ${ }^{87,88}$ stated clearly that stroke was not associated with high plasma renin and speculated that there were differences in the etiology of coronary heart disease and stroke, or, alternatively, different relationships between the reninangiotensin system and the coronary and cerebral vasculatures, respectively. Therefore, the discrepancy between previous reports ${ }^{87,88}$ and our hypothesis may be ascribed to the difference in cardiovascular events (for example, coronary heart disease or stroke) or in race (white or Japanese). It is also interesting that high salt sensitivity is more common in people of Japanese origin, and strokes are seen more frequently than ischemic heart disease. Similarly, people of African origin are more salt sensitive than Caucasians, ${ }^{89,90}$ and strokes are known to be more common in the former group. ${ }^{91,92}$ Thus, there may be a link between salt sensitivity and stroke among Japanese and African Americans.

Primary aldosteronism is one of the most typical forms of salt-sensitive hypertension. ${ }^{3,34,93}$ We found 9 cases (15.5\%) of stroke in 58 patients with primary aldosteronism, ${ }^{94}$ which is consistent with other reports. ${ }^{95}$ These findings support our proposal for an association between the salt-sensitive type of hypertension and stroke. It should be noted that the incidence of stroke in patients with primary aldosteronism was approximately twice if proteinuria was present. ${ }^{94}$

\section{CKD AND STROKE}

In CKD (one of the major forms of salt-sensitive hypertension) with estimated GFR less than $60 \mathrm{ml} \mathrm{min}^{-1}$ per $1.73 \mathrm{~m}^{2}$, stroke incidence was reported to be increased in the Tsukuba study. ${ }^{96}$ It should be emphasized, on the other hand, that the incidence of coronary heart disease did not increase. ${ }^{96}$ On the contrary, the Hisayama study ${ }^{97}$ showed the different findings because in men the incidence of stroke was not increased, whereas the incidence of coronary heart disease was increased in CKD. In women, on the other hand, the incidence of stroke due to cerebral infarction was significantly increased, but the incidence of coronary heart disease was not increased, which is consistent with the findings by the Tsukuba study. In the Hisayama study, the reason creating such gender difference was not discussed, and the total number of cardiovascular events was increased in CKD only in women. Therefore, these findings obtained in both Tsukuba and Hisayama studies may consistently suggest that that the frequency of stroke is increased in CKD. Whether the incidence of coronary 
heart disease is also increased in CKD among Japanese must be studied further.

\section{PATHOPHYSIOLOGY OF THE CARDIORENAL CONNECTION}

The remarkable increases in cardiovascular events among hemodialysis patients are widely recognized. ${ }^{98-101}$ It is important to understand the precise mechanisms underlying the increase in cardiovascular events as renal function deteriorates and the capacity to excrete sodium into the urine is impaired, even in mild degree. ${ }^{13,17,102}$

As discussed above, the incidence of stroke is increased in both saltsensitive hypertension and CKD. Bongartz et al. ${ }^{103,104}$ have proposed that cardiovascular overload due to renal dysfunction and heart failure induces an imbalance between nitric oxide and oxidative stress as well as mild inflammation and activates the sympathetic nervous as well as tissue renin-angioten $\sin ^{105}$ systems, eventually resulting in cardiovascular events. Because pressure overload in the systemic circulation is the first trigger according to the accepted hypothesis, it is easy to understand that stroke and heart failure are frequently associated in patients with salt-sensitive type of hypertension and non-dipper pattern of circadian BP rhythm. In fact, the cumulative incident rate of heart failure was significantly higher in non-dipper than in dippers, ${ }^{106}$ which is consistent with the hypothesis. This hypothesis may also explain why inhibitors of the renin-angiotensin system efficiently prevent cardiovascular events, especially in patients with $\mathrm{CKD}^{15,107}$ and high salt sensitivity.

We propose that salt sensitivity of BP and excess salt intake have an important role in the genesis of cardiorenal connections (Figure 3). When either glomerular ultrafiltration capabilities are reduced or tubular sodium reabsorption is enhanced, BP becomes salt sensitive and glomerular capillary pressure is elevated. Therefore, load to the glomerulus is increased, resulting in glomerular sclerosis and eventual renal failure. In addition, the circadian BP rhythm becomes the nondipper pattern to enhance pressure natriuresis during the night, whereas nocturnal hypertension causes cardiovascular events. In this way, salt sensitivity and excess salt intake contribute to the cardiorenal

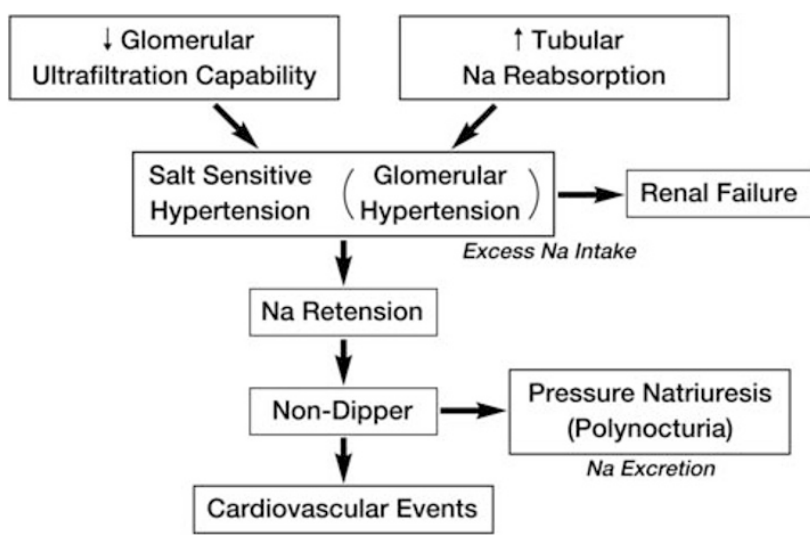

Figure 3 Cardiorenal connection and salt sensitivity of blood pressure. We propose that blood pressure (BP) salt sensitivity and excess salt intake have an important role in the genesis of a cardiorenal connection. When glomerular ultrafiltration capabilities are reduced or tubular sodium reabsorption is enhanced, BP becomes salt sensitive and glomerular capillary pressure is elevated. Therefore, the glomerular load is increased, resulting in glomerular sclerosis and eventual renal failure. In addition, circadian BP rhythm becomes non-dipper to enhance pressure natriuresis during the night, whereas nocturnal hypertension causes cardiovascular events. In this way, salt sensitivity and excess salt intake contribute greatly to the cardiorenal connection. connection. Because pressure overload is increased in salt-sensitive hypertension, it is easy to understand why stroke, heart failure and renal failure are frequently associated with renal dysfunction. However, it is difficult to understand why coronary heart disease is also frequently associated with renal dysfunction. The mechanisms explaining how cardiovascular events are increased as renal function deteriorates may differ in stroke and coronary heart disease. The renin-angiotensin system and atherosclerosis may have major roles in coronary heart disease.

\section{CONCLUSION}

Salt intake restriction has been considered one of the most important lifestyle modifications in the field of hypertension and renal diseases. ${ }^{108}$ Nevertheless, there is no consensus on its importance in arresting cardiorenal complications. As discussed above, salt restriction in patients with high salt sensitivity may lower systemic and glomerular capillary pressure, reduce proteinuria and normalize circadian BP rhythm from a non-dipper pattern to a dipper one. Therefore, salt restriction may relieve these risks and prevent cardiovascular and renal diseases. We believe that both salt sensitivity and a non-dipper pattern of circadian BP rhythm must be recognized as important prognostic predictors for cardiorenal diseases. Salt sensitivity and a non-dipper pattern reflect the loss of renal functional reserve and severity of hypertension that cannot be predicted by classic factors such as BP itself, risk factors and target organ damage.

\section{ACKNOWLEDGEMENTS}

This work was supported by Research Grants for Cardiovascular Diseases (C-2001-5) from the Ministry of Health and Welfare of Japan, as well as grants from Nagoya City University, Salt Science Research Foundation (No. 04C1), the Metabolic Disorders Treatment Research Foundation, the Aichi Kidney Foundation, the Japan Cardiovascular Research Foundation and a Grant-in-Aid for Scientific Research (B\#19390232 \& C\#17590836) from the Ministry of Education, Culture, Sports, Science and Technology of Japan obtained through the Japan Society for the Promotion of Science.

1 Kearney PM, Whelton M, Reynolds K, Muntner P, Whelton PK, He J. Global burden of hypertension: analysis of worldwide data. Lancet 2005; 365: 217-223.

2 Guyton AC. Dominant role of the kidneys and accessory role of whole-body autoregulation in the pathogenesis of hypertension. Am J Hypertens 1989; 2: 575-585.

3 Kimura G, Saito F, Kojima S, Yoshimi H, Abe H, Kawano Y, Yoshida K, Ashida T, Kawamura M, Kuramochi M, Ito K, Omae T. Renal function curve in patients with secondary forms of hypertension. Hypertension 1987; 10: 11-15.

4 Kimura G, Saito F, Deguchi F, Abe H, Yoshida K, Kawano Y, Yoshimi H, Kojima S, Yokouchi M, Kawamura M, Natsume T, Kuramochi M, Ito K, Omae T. Water tank model on body fluid volume versus blood pressure regulation. J Hypertens 1986; 4(Suppl 5): S192-S194.

5 Kimura G, Abe H, Ashida T, Kawano Y, Yoshimi H, Imanishi M, Kawamura M, Kojima $\mathrm{S}$, Yoshida K, Kuramochi M, Omae T. Hypotensive mechanisms of antihypertensives based on the water tank model. Am J Hypertens 1989; 2: 532-536.

6 Kimura G, Ashida T, Abe H, Kawano Y, Yoshimi H, Sanai T, Imanishi M, Yoshida K, Kawamura M, Kojima S, Kuramochi M, Omae T. Sodium sensitive and sodium retaining hypertension. Am J Hypertens 1990; 3: 854-858.

7 Kimura G, Brenner BM. The renal basis for salt sensitivity in hypertension. In Laragh, JH, Brenner, BM (eds), Hypertension: Pathophysiology, Diagnosis and Management, Vol 2. Raven Press: New York, 1995, pp. 1569-1588.

8 Coffman TM, Crowley SD. Kidney in hypertension: guyton redux. Hypertension 2008; 51: 811-816.

9 Dorrington $\mathrm{KL}$, Pandit JJ. The obligatory role of the kidney in long-term arterial blood pressure control: extending Guyton's model of the circulation. Anaesthesia 2009; 64: 1218-1228.

10 Gerstein HC, Mann JF, Yi Q, Zinman B, Dinneen SF, Hoogwerf B, Halle JP, Young J, Rashkow A, Joyce C, Nawaz S, Yusuf S. Albuminuria and risk of cardiovascular events, death, and heart failure in diabetic and nondiabetic individuals. JAMA 2001; 286: 421-426.

11 Hillege HL, Fidler V, Diercks GF, van Gilst WH, de Zeeuw D, van Veldhuisen DJ, Gans $\mathrm{RO}$, Janssen WM, Grobbee DE, de Jong PE. Urinary albumin excretion predicts 
cardiovascular and noncardiovascular mortality in general population. Circulation 2002; 106: 1777-1782.

12 Valmadrid CT, Klein R, Moss SE, Klein BE. The risk of cardiovascular disease mortality associated with microalbuminuria and gross proteinuria in persons with older-onset diabetes mellitus. Arch Intern Med 2000; 160: 1093-1100.

13 Muntner P, He J, Hamm L, Loria C, Whelton PK. Renal insufficiency and subsequent death resulting from cardiovascular disease in the United States. J Am Soc Nephrol 2002; 13: 745-753.

14 Ibsen $H$, Olsen MH, Wachtell K, Borch-Johnsen K, Lindholm LH, Mogensen CE, Dahlof B, Devereux RB, de Faire U, Fyhrquist F, Julius S, Kjeldsen SE, LederballePedersen O, Nieminen MS, Omvik P, Oparil S, Wan Y. Reduction in albuminuria translates to reduction in cardiovascular events in hypertensive patients: Iosartan intervention for endpoint reduction in hypertension study. Hypertension 2005; 45 : 198-202.

15 Mann JF, Gerstein HC, Pogue J, Bosch J, Yusuf S. Renal insufficiency as a predictor of cardiovascular outcomes and the impact of ramipril: the HOPE randomized trial. Ann Intern Med 2001; 134: 629-636.

16 Ruilope LM, Salvetti A, Jamerson K, Hansson L, Warnold I, Wedel H, Zanchetti A. Renal function and intensive lowering of blood pressure in hypertensive participants of the hypertension optimal treatment (HOT) study. J Am Soc Nephrol 2001; 12: 218-225.

17 Go AS, Chertow GM, Fan D, McCulloch CE, Hsu CY. Chronic kidney disease and the risks of death, cardiovascular events, and hospitalization. N Engl J Med 2004; 351 1296-1305.

18 Sarnak MJ, Levey AS, Schoolwerth AC, Coresh J, Culleton B, Hamm LL, McCullough PA, Kasiske BL, Kelepouris E, Klag MJ, Parfrey P, Pfeffer M, Raij L, Spinosa DJ, Wilson PW. Kidney disease as a risk factor for development of cardiovascular disease: a statement from the American Heart Association Councils on Kidney in Cardiovascular Disease, High Blood Pressure Research, Clinical Cardiology, and Epidemiology and Prevention. Circulation 2003; 108: 2154-2169.

19 National Kidney Foundation. K/DOQI clinical practice guidelines for chronic kidney disease: evaluation, classification, and stratification. Am J Kidney Dis 2002; 39(2 Suppl 1): S1-S266.

20 Morimoto A, Uzu T, Fujii T, Nishimura M, Kuroda S, Nakamura S, Inenaga T, Kimura G. Sodium sensitivity and cardiovascular events in patients with essential hypertension. Lancet 1997; 350: 1734-1737.

21 Kimura G. Sodium sensitivity of blood pressure: a new prognostic factor in hypertension. Nephron 1999; 83: 97-105.

22 Kimura G, Imanishi M, Sanai T, Kawano Y, Kojima S, Yoshida K, Abe H, Ashida T, Yoshimi H, Kawamura M, Kuramochi M, Omae T. Intrarenal hemodynamics in patients with essential hypertension. Circ Res 1991; 69: 421-428.

23 Saito F, Kimura G. Antihypertensive mechanism of diuretics based on pressurenatriuresis relationship. Hypertension 1996; 27: 914-918.

24 Kimura G, Brenner BM. Implications of linear pressure-natriuresis relationship and importance of sodium sensitivity in hypertension. J Hypertens 1997; 15: 1055-1061.

25 Akita S, Sacks FM, Svetkey LP, Conlin PR, Kimura G. Effects of the Dietary Approaches to Stop Hypertension (DASH) diet on the pressure-natriuresis relationship. Hypertension 2003; 42: 8-13.

26 Weinberger MH, Fineberg NS, Fineberg SE, Weinberger M. Salt sensitivity, pulse pressure, and death in normal and hypertensive humans. Hypertension 2001; 37(2 Part 2): 429-432.

27 Kimura G, Frem GJ, Brenner BM. Renal mechanisms of salt sensitivity in hypertension. Curr Opin Nephrol Hypertens 1994; 3: 1-12.

28 Kimura G. Glomerular function reserve and sodium sensitivity. Clin Exp Nephrol 2005: 9: 102-113.

29 Kimura G. Kidney and circadian blood pressure rhythm. Hypertension 2008; 51: 827-828.

30 Kimura G. Sodium, kidney, and circadian rhythm of blood pressure. Clin Exp Nephrol 2001; 5: 13-18.

31 Fukuda M, Goto N, Kimura G. Hypothesis on renal mechanism of non-dipper pattern of circadian blood pressure rhythm. Med Hypotheses 2006; 67: 802-806.

32 Uzu T, Kazembe FS, Ishikawa K, Nakamura S, Inenaga T, Kimura G. High sodium sensitivity implicates nocturnal hypertension in essential hypertension. Hypertension 1996; 28: 139-142.

33 Uzu T, Ishikawa K, Fujii T, Nakamura S, Inenaga T, Kimura G. Sodium restriction shifts circadian rhythm of blood pressure from nondipper to dipper in essential hypertension. Circulation 1997; 96: 1859-1862.

34 Uzu T, Nishimura M, Fujii T, Takeji M, Kuroda S, Nakamura S, Inenaga T, Kimura G. Changes in the circadian rhythm of blood pressure in primary aldosteronism in response to dietary sodium restriction and adrenalectomy. J Hypertens 1998; 16: $1745-1748$.

35 Kimura G, Brenner BM. A method for distinguishing salt-sensitive from nonsalt-sensitive forms of human and experimental hypertension. Curr Opin Nephrol Hypertens 1993; 2: 341-349.

36 Kimura G, Sanai T, Saito F, Uzu T. Renal determinants for sodium sensitivity of blood pressure. Hypertension 1996; 28: 1102-1103.

37 Fujii T, Uzu T, Nishimura M, Takeji M, Kuroda S, Nakamura S, Inenaga T, Kimura G. Circadian rhythm of natriuresis is disturbed in non-dipper type of essential hypertension. Am J Kidney Dis 1999; 33: 29-35.

38 Fukuda M, Munemura M, Usami T, Nakao N, Takeuchi O, Kamiya Y, Yoshida A, Kimura G. Nocturnal blood pressure is elevated with natriuresis and proteinuria as renal function deteriorates in nephropathy. Kidney Int 2004; 65: 621-625.
39 Fukuda M, Motokawa M, Miyagi S, Sengo K, Muramatsu W, Kato N, Usami T, Yoshida A, Kimura G. Polynocturia in chronic kidney disease is related to natriuresis rather than to water diuresis. Nephrol Dial Transplant 2006; 21: 2172-2177.

40 Goto N, Uchida K, Morozumi K, Ueki T, Matsuoka S, Katayama A, Haba T, Tominaga Y, Fukuda M, Nakao A, Kimura G. Circadian blood pressure rhythm is disturbed by nephrectomy. Hypertens Res 2005; 28: 301-306.

41 Cianciaruso B, Bellizzi V, Minutolo R, Colucci G, Bisesti V, Russo D, Conte G, De Nicola L. Renal adaptation to dietary sodium restriction in moderate renal failure resulting from chronic glomerular disease. J Am Soc Nephrol 1996; 7: 306-313.

42 Konishi Y, Okada N, Okamura M, Morikawa T, Okumura M, Yoshioka K, Imanishi M. Sodium sensitivity of blood pressure appearing before hypertension and related to histological damage in immunoglobulin A nephropathy. Hypertension 2001; 38: 81-85.

43 Koomans HA, Roos JC, Boer P, Geyskes GG, Dorhout Mees EJ. Salt sensitivity of blood pressure in chronic renal failure. Evidence for renal control of body fluid distribution in man. Hypertension 1982; 4: 190-197.

44 Kumagai $\mathrm{H}$, Onoyama K, Fujishima M. Effects of salt restriction on blood volume, hemodynamics and humoral factors in patients with chronic glomerulonephritis. Am J Hypertens 1989; 2: 669-674.

45 Brenner BM, Garcia DL, Anderson S. Glomeruli and blood pressure. Less of one, more the other? Am J Hypertens 1988; 1: 335-347.

46 Kimura G, Brenner BM. Indirect assessment of glomerular capillary pressure from pressure-natriuresis relationship: Comparison with direct measurements reported in rats. Hypertens Res 1997; 20: 143-148.

47 Timio M, Venanzi S, Lolli S, Lippi G, Verdura C, Monarca C, Guerrini E. 'Non-dipper' hypertensive patients and progressive renal insufficiency: a 3-year longitudinal study. Clin Nephrol 1995; 43: 382-387.

48 Nakano S, Ogihara M, Tamura C, Kitazawa M, Nishizawa M, Kigoshi T, Uchida K. Reversed circadian blood pressure rhythm independently predicts endstage renal failure in non-insulin-dependent diabetes mellitus subjects. J Diabetes Complications 1999; 13: 224-231.

49 Csiky B, Kovacs T, Wagner L, Vass T, Nagy J. Ambulatory blood pressure monitoring and progression in patients with IgA nephropathy. Nephrol Dial Transplant 1999; 14: 86-90.

50 Lurbe E, Redon J, Kesani A, Pascual JM, Tacons J, Alvarez V, Batlle D. Increase in nocturnal blood pressure and progression to microalbuminuria in type 1 diabetes. $N$ Engl J Med 2002; 347: 797-805.

51 Paoletti E, Bellino D, Amidone M, Rolla D, Cannella G. Relationship between arteria hypertension and renal damage in chronic kidney disease: insights from ABPM. J Nephrol 2006; 19: 778-782

52 Davidson MB, Hix JK, Vidt DG, Brotman DJ. Association of impaired diurnal blood pressure variation with a subsequent decline in glomerular filtration rate. Arch Intern Med 2006; 166: 846-852.

53 Rosansky SJ, Johnson KL, Hutchinson C, Erdel S. Blood pressure changes during daytime sleep and comparison of daytime and nighttime sleep-related blood pressure changes in patients with chronic renal failure. J Am Soc Nephrol 1993; 4: 1172-1177.

54 Baumgart P, Walger P, Gemen S, von Eiff M, Raidt H, Rahn KH. Blood pressure elevation during the night in chronic renal failure, hemodialysis and after renal transplantation. Nephron 1991; 57: 293-298.

55 Gatzka CD, Schobel HP, Klingbeil AU, Neumayer HH, Schmieder RE. Normalization of circadian blood pressure profiles after renal transplantation. Transplantation J 1995; 59: $1270-1274$

56 Uzu T, Kimura G. Diuretics shift circadian rhythm of blood pressure from nondipper to dipper in essential hypertension. Circulation 1999; 100: 1635-1638.

57 Takakuwa H, Shimizu K, Izumiya Y, Kato T, Nakaya I, Yokoyama H, Kobayashi K, Ise T. Dietary sodium restriction restores nocturnal reduction of blood pressure in patients with primary aldosteronism. Hypertens Res 2002; 25: 737-742.

58 Nishijima K, Tochikubo 0 . Relation between sodium intake and blood pressure during sleep in young men. Hypertens Res 2003; 26: 135-140.

59 Fukuda M, Mizuno M, Yamanaka T, Motokawa M, Shirasawa Y, Nishio T, Miyagi S, Yoshida A, Kimura G. Patients with renal dysfunction require a longer duration until blood pressure dips during the night. Hypertension 2008; 52: 1155-1160.

60 Sanai T, Kimura G. Renal function reserve and sodium sensitivity in essential hypertension. J Lab Clin Med 1996; 128: 89-97.

61 Rocchini AP, Katch V, Kveselis D, Moorehead C, Martin M, Lampman R, Gregory M. Insulin and renal sodium retention in obese adolescents. Hypertension 1989; 14: 367-374.

62 Sharma AM, Schorr U, Distler A. Insulin resistance in young salt-sensitive normotensive subjects. Hypertension 1993; 21: 273-279.

63 Falkner B, Hulman S, Kushner H. Hyperinsulinemia and blood pressure sensitivity to sodium in young blacks. J Am Soc Nephrol 1992; 3: 940-946.

64 Kuroda S, Uzu T, Fujii T, Nishimura M, Nakamura S, Inenaga T, Kimura G. Role of insulin resistance in the genesis of sodium sensitivity in essential hypertension. J Hum Hypertens 1999; 13: 257-262.

65 Uzu T, Kimura G, Yamauchi A, Kanasaki M, Isshiki K, Araki S, Sugiomoto T, Nishio Y, Maegawa H, Koya DF, Haneda M, Kashiwagi A. Enhanced sodium sensitivity and disturbed circadian rhythm of blood pressure in essential hypertension. $J$ Hypertens 2006; 24: 1627-1632.

66 Chen J, Gu D, Huang J, Rao DC, Jaquish CE, Hixson JE, Chen CS, Lu F, Hu D, Rice T, Kelly TN, Hamm LL, Whelton PK, He J. Metabolic syndrome and salt sensitivity of blood pressure in non-diabetic people in China: a dietary intervention study. Lancet 2009; 373: 829-835. 
67 O'Brien E, Sheridan J, O'Malley K. Dippers and non-dippers. Lancet 1988; 2: 397.

68 Pickering TG. The clinical significance of diurnal blood pressure variations. Dippers and nondippers. Circulation 1990; 81: 700-702

69 Verdecchia P, Schillaci G, Porcellati C. Dippers versus non-dippers. J Hypertens 1991; 9(Suppl 8): S42-S44.

70 Verdecchia P, Schillaci G, Guerrieri M, Gatteschi C, Benemio G, Boldrini F, Porcellati C. Circadian blood pressure changes and left ventricular hypertrophy in essential hypertension. Circulation 1990; 81: 528-536.

71 Bianchi S, Bigazzi R, Baldari G, Sgherri G, Campese VM. Diurnal variations of blood pressure and microalbuminuria in essential hypertension. Am J Hypertens 1994; 7: 23-29.

72 Shimada K, Kawamoto A, Matsubayashi K, Ozawa T. Silent cerebrovascular disease in the elderly. Correlation with ambulatory pressure. Hypertension 1990; 16: 692-699.

73 Verdecchia P, Porcellati C, Schillaci G, Borgioni C, Ciucci A, Battistelli M, Guerrieri M, Gatteschi C, Zampi I, Santucci A, Santucci C, Reboldi G. Ambulatory blood pressure. An independent predictor of prognosis in essential hypertension. Hypertension 1994; 24: 793-801.

74 Kuusisto J, Mykkanen L, Pyorala K, Laakso M. Hyperinsulinemic microalbuminuria. A new risk indicator for coronary heart disease. Circulation 1995; 91: 831-837.

75 Bigazzi R, Bianchi S, Baldari D, Campese VM. Microalbuminuria predicts cardiovascular events and renal insufficiency in patients with essential hypertension. J Hypertens 1998; 16: 1325-1333.

76 Yoshioka T, Rennke HG, Salant DJ, Deen WM, Ichikawa I. Role of abnormally high transmural pressure in the permselectivity defect of glomerular capillary wall: a study in early passive Heymann nephritis. Circ Res 1987; 61: 531-538.

77 Imanishi M, Yoshioka K, Okumura M, Konishi Y, Tanaka S, Fujii S, Kimura G. Mechanism of decreased albuminuria caused by angiotensin converting enzyme inhibitor in early diabetic nephropathy. Kidney Int 1997; 63 (Suppl): S198-S200.

78 Howard G, O'Leary DH, Zaccaro D, Haffner S, Rewers M, Hamman R, Selby JV, Saad MF, Savage P, Bergman R. Insulin sensitivity and atherosclerosis. The Insulin Resistance Atherosclerosis Study (IRAS) Investigators. Circulation 1996; 93: 1809-1817.

79 Reaven GM. Role of insulin resistance in human disease. Diabetes 1988; 37 : 1595-1607.

80 Kaplan NM. The deadly quartet. Upper-body obesity, glucose intolerance, hypertriglyceridemia, and hypertension. Arch Intern Medicine 1989; 149: 1514-1520.

81 Matsuzawa Y, Shimomura I, Nakamura T, Keno Y, Tokunaga K. Pathophysiology and pathogenesis of visceral fat obesity. Ann NY Acad Sci 1995; 748: 399-406.

82 Campese VM. Salt sensitivity in hypertension. Renal and cardiovascular implications. Hypertension 1994; 23: 531-550.

83 Cappuccio FP, Strazzullo P, Siani A, Trevisan M. Increased proximal sodium reabsorption is associated with increased cardiovascular risk in men. J Hypertens 1996; 14: 909-914.

84 Bigazzi R, Bianchi S, Baldari G, Campese VM. Clustering of cardiovascular risk factors in salt-sensitive patients with essential hypertension: role of insulin. Am J Hypertens 1996; 9: 24-32.

85 Whaley-Connell A, Sowers JR. Obesity, insulin resistance, and nocturnal systolic blood pressure. Hypertension 2008; 51: 620-621.

86 Lurbe E, Torro I, Aguilar F, Alvarez J, Alcon J, Pascual JM, Redon J. Added impact of obesity and insulin resistance in nocturnal blood pressure elevation in children and adolescents. Hypertension 2008; 51: 635-641.

87 Alderman MH, Madhavan S, Ooi WL, Cohen H, Sealey JE, Laragh JH. Association of the renin-sodium profile with the risk of myocardial infarction in patients with hypertension. N Engl J Med 1991; 324: 1098-1104.

88 Alderman MH, Ooi WL, Cohen H, Madhavan S, Sealey JE, Laragh JH. Plasma renin activity: a risk factor for myocardial infarction in hypertensive patients. Am J Hypertens 1997; 10: 1-8.
89 Luft FC, Miller JZ, Grim CE, Fineberg NS, Christian JC, Daugherty SA, Weinberger $\mathrm{MH}$. Salt sensitivity and resistance of blood pressure. Age and race as factors in physiological responses. Hypertension 1991; 17(Suppl I): I102-I108.

90 Parmer RJ, Stone RA, Cervenka JH. Renal hemodynamics in essential hypertension. Racial differences in response to changes in dietary sodium. Hypertension 1994; 24 : 752-757.

91 Caplan LR. Strokes in African-Americans. Circulation 1991; 83: 1469-1471.

92 Broderick JP, Brott T, Tomsick T, Huster G, Miller R. The risk of subarachnoid and intracerebral hemorrhages in blacks as compared with whites. N Engl J Med 1992; 326: 733-736.

93 Kimura G, Uzu T, Nakamura S, Inenaga T, Fujii T. High sodium sensitivity and glomerular hypertension/hyperfiltration in primary aldosteronism. J Hypertens 1996; 14: $1463-1468$.

94 Nishimura M, Uzu T, Fujii T, Kuroda S, Nakamura S, Inenaga T, Kimura G. Cardiovascular complications in patients with primary aldosteronism. Am J Kidney Dis 1999; 33: 261-266.

95 Beevers DG, Brown JJ, Ferriss JB, Fraser R, Lever AF, Robertson JI, Tree M. Renal abnormalities and vascular complications in primary aldosteronism. Quart J Med 1976; 45: 401-410.

96 Irie F, Iso H, Sairenchi T, Fukasawa N, Yamagishi K, Ikehara S, Kanashiki M, Saito Y, Ota $\mathrm{H}$, Nose $\mathrm{T}$. The relationships of proteinuria, serum creatinine, glomerular filtration rate with cardiovascular disease mortality in Japanese general population. Kidney Int 2006; 69: 1264-1271.

97 Ninomiya T, Kiyohara Y, Kubo M, Tanizaki Y, Doi Y, Okubo K, Wakugawa $Y$, Hata J, Oishi Y, Shikata K, Yonemoto K, Hirakata H, lida M. Chronic kidney disease and cardiovascular disease in a general Japanese population: the Hisayama Study. Kidney Int 2005; 68: 228-236.

98 Tomita J, Kimura G, Inoue T, Inenaga T, Sanai T, Kawano Y, Nakamura S, Baba S, Matsuoka H, Omae T. Role of systolic blood pressure in determining prognosis of hemodialyzed patients. Am J Kidney Dis 1995; 25: 405-412.

99 Kimura G, Tomita J, Nakamura S, Uzu T, Inenaga T. Interaction between hypertension and other cardiovascular risk factors in survival of hemodialyzed patients. Am J Hypertens 1996; 9(10 Part 1): 1006-1012.

100 Wheeler DC. Cardiovascular disease in patients with chronic renal failure. Lancet 1996; 348: 1673-1674.

101 Foley RN, Parfrey PS, Sarnak MJ. Epidemiology of cardiovascular disease in chronic renal disease. J Am Soc Nephrol 1998; 9(12 Suppl): S16-S23.

102 Schillaci G, Reboldi G, Verdecchia P. High-normal serum creatinine concentration is a predictor of cardiovascular risk in essential hypertension. Arch Intern Med 2001; 161: 886-891.

103 Bongartz LG, Cramer MJ, Braam B. The cardiorenal connection. Hypertension 2004; 43: e14.

104 Bongartz LG, Cramer MJ, Doevendans PA, Joles JA, Braam B. The severe cardiorenal syndrome: 'Guyton revisited'. Eur Heart J 2005; 26: 11-17.

105 Schiffrin EL. Effects of aldosterone on the vasculature. Hypertension 2006; 47 : 312-318.

106 Ingelsson E, Bjorklund-Bodegard K, Lind L, Arnlov J, Sundstrom J. Diurnal blood pressure pattern and risk of congestive heart failure. JAMA 2006; 295: 2859-2866.

107 Solomon SD, Rice MM, Jablonski KA, Jose P, Domanski M, Sabatine M, Gersh BJ, Rouleau J, Pfeffer MA, Braunwald E. Renal function and effectiveness of angiotensinconverting enzyme inhibitor therapy in patients with chronic stable coronary disease in the Prevention of Events with ACE inhibition (PEACE) trial. Circulation 2006; 114: 26-31.

108 He FJ, MacGregor GA. A comprehensive review on salt and health and current experience of worldwide salt reduction programmes. J Hum Hypertens 2009; 23 : 363-384. 